TITLE:

\title{
Multivariate analysis of nitrogen content for rice at the heading stage using reflectance of airborne hyperspectral remote sensing
}

$\operatorname{AUTHOR}(\mathrm{S})$ :

Ryu, Chanseok; Suguri, Masahiko; Umeda, Mikio

CITATION:

Ryu, Chanseok ... [et al]. Multivariate analysis of nitrogen content for rice at the heading stage using reflectance of airborne hyperspectral remote sensing. Field Crops Research 2011, 122(3): 214-224

ISSUE DATE:

2011-06

URL:

http://hdl.handle.net/2433/142952

RIGHT:

(c) 2011 Elsevier B.V.; この論文は出版社版でありません。引用の際には 出版社版をご確認ご利用ください。; This is not the published version. Please cite only the published version. 


\title{
Multivariate Analysis of Nitrogen Content for Rice at the Heading Stage Using Reflectance of Airborne Hyperspectral Remote Sensing
}

\author{
Chanseok Ryu ${ }^{a^{*}}$, Masahiko Suguri ${ }^{\mathrm{a}}$, and Mikio Umeda ${ }^{\mathrm{b}}$ \\ ${ }^{a}$ Environmental Science and Technology, Graduate School of Agriculture, \\ Kyoto University, Sakyo-ku, Kitashirakawa Oiwake-cho, Kyoto 606-8502, Japan \\ ${ }^{b}$ Senior Director of Career Support Center,
}

Kyoto University, Sakyo-ku, Honmachi Yoshida, Kyoto 606-8501, Japan

\begin{abstract}
Airborne hyperspectral remote sensing was adapted to establish a general-purpose model for quantifying nitrogen content of rice plants at the heading stage using three years of data. There was a difference in dry mass and nitrogen concentration due to the difference in the accumulated daily radiation (ADR) and effective cumulative temperature (ECT). Because of these environmental differences, there was also a significant difference in nitrogen content among the three years. In the multiple linear regression (MLR) analysis, the accuracy (coefficient of determination: $\mathrm{R}^{2}$, root mean square of error: RMSE and relative error: RE) of two-year models was better than that of single-year models as shown by $\mathrm{R}^{2} \geq 0.693$, RMSE $\leq 1.405 \mathrm{gm}^{-2}$ and $\mathrm{RE} \leq 9.136 \%$. The accuracy of the three-year model was $\mathrm{R}^{2}=0.893$, $\mathrm{RMSE}=1.092 \mathrm{gm}^{-2}$ and $\mathrm{RE}=8.550 \%$ with eight variables. When each model was verified using the other data, the range of RE for two-year models was similar or increased compared with that for single-year models. In the partial least square regression (PLSR) model for the validation, the accuracy of two-year models was also better than that of single-year models as $R^{2} \geq 0.699$, RMSE $\leq 1.611 \mathrm{gm}^{-2}$ and $\mathrm{RE} \leq 13.36 \%$. The accuracy of the three-year model was $\mathrm{R}^{2}=0.837$, $\mathrm{RMSE}=1.401 \mathrm{gm}^{-2}$ and $\mathrm{RE}=11.23 \%$ with four latent variables. When each model was verified, the range of RE for two-year models was similar or decreased compared with that for single-year models. The similarities and differences of loading weights for each latent variable depending on hyperspectral reflectance might have affected the regression coefficients and the accuracy of each prediction model. The accuracy of the single-year MLR models was better than that of the single-year PLSR models. However, accuracy of the multi-year PLSR models was better than that of the multi-year MLR models. Therefore, PLSR model might be more suitable than MLR model to predict the nitrogen contents at the heading stage using the hyperspectral reflectance because PLSR models have more sensitive than MLR models for the inhomogeneous results. Although there were differences in the environmental variables (ADR and ECT), it is possible to establish a general-purpose prediction model for nitrogen content at the heading stage using airborne hyperspectral remote sensing.
\end{abstract}


Keywords: airborne hyperspectral remote sensing, nitrogen content, heading stage, multiple linear regression (MLR), partial least square regression (PLSR)

*Corresponding author. Tel.: +81-75-753-6317; Fax: +81-75-753-6167; E-mail: ryu@elam.kais.kyotou.ac.jp

\section{Introduction}

Agronomically, there are three growth stages in rice: vegetative, reproductive pre-heading, and reproductive post-heading. The vegetative stage refers to the period from germination to the initiation of panicle; the pre-heading period from panicle initiation to heading; and the post-heading period from heading to maturity (Yoshida, 1981). Therefore, it is important to study the growth and nitrogen content status at the panicle initiation, heading and maturity stages for precision agriculture, which is a management practice and a framework within which agricultural managers can more accurately understand and control what happens in their farms (Blackmore, 1994). The growth of rice plants, and the quality and quantity of rice grains are extremely sensitive to nitrogen fertilizer and climatic conditions such as the intensity and duration of sunshine, air and water temperature, and the available water supply (Inoue et al., 1963). The amount of nitrogen content at the heading stage is mainly affected by the amount of nitrogen fertilizer at topdressing, which is calculated based on the amount of nitrogen content at the panicle initiation stage and the uptake of nitrogen from the soil (Ryu et al., 2009). There have been the several studies on the growth and nitrogen content status in the vegetative and reproductive pre-heading stages with the controlled application timing and amount of nitrogen fertilizer application, which was used to artificially control the quality and quantity of rice grain (Takahashi et al., 2000; Casanova et al., 2000; Ryu et al., 2010b). However, the quality and quantity of rice grains are closely related to the growth and nitrogen content status at the heading stage (Ntanos and Koutroubas, 2002). Thus, it is also important to identify the growth and nitrogen content status of rice plants at the heading stage. Moreover, it has also been confirmed that variable rate fertilizer application is adoptable for controlling the growth and nitrogen content status of rice plants uniformly. As one way of identifying the growth and nitrogen status of rice plants, remote sensing has great potential because it enables wide-area, non-destructive, and real-time acquisition of information on ecophysiological plant conditions (Inoue, 2003; Chang et al., 2005).

A great deal of research effort has been directed towards the assessment of crop yield and ecophysiological variables using remote sensing in optical, thermal, and microwave wavelength domains together with modeling approaches (Inoue et al., 2008). With remote sensing from satellites, however, the cloud coverage ratio (CCR) causes limitations because thick clouds frequently prohibit normal data acquisition in the early to mid-summer rainy season in monsoon Asia (Inoue et al., 2002; Shibayama et al., 2009). 
Moreover, broadband data from multi spectral sensors often lose critical information that is available in specific narrow bands (Blackburn, 1998) and has proven difficult to discriminate the variation in vegetation composition (Lewis et al., 2001). Recent advances in ground-based, airborne hyperspectral sensing indicates that the selection of new wavebands has been carried out in a number of cases focusing on how to find out the most sensitive wavebands related to biophysical, physiological or biochemical characteristics (Zarco-Tehada et al., 2001; Thenkabail et al., 2000; Evri et al., 2008).

Research on hyperspectral remote sensing for rice plants has been separated into two groups: (1) narrow-band vegetation indices and (2) multivariate analysis (Inoue and Penuelas, 2001). In the case of rice plants, the simple ratio of two narrow bands was studied to detect the biophysical, physiological or biochemical characteristics (Casanova et al., 1998; Kimura et al., 2004; Wang et al., 2007; Lee et al., 2008; Stroppiana et al., 2009), to estimate the gross ecosystem production (Inoue et al., 2008; Micol et al., 2010) and to discriminate and detect disease (Liu et al., 2008; Yang, 2010). Multivariate analysis models provided flexibility in choosing individual narrow bands and improved the models' ability to estimate plant growth, as compared with those estimated from spectral indices and a single narrow band (Yang and Chen 2004; Yi et al., 2007). Therefore, multivariate analysis, multiple linear regression (MLR), principal components analysis (PCA) and partial least square regression (PLSR) was applied to estimate the biophysical, physiological or biochemical characteristics of rice plants. Nguyen and Lee (2006) established the variation of crop growth and nitrogen status within a field using PLSR. Chen et al., (2003) compared the precision of the model for chlorophyll content between vegetation indices and MLR. Yi et al., (2007) compared the precision of the estimation model for nitrogen concentration depending on several multivariate analyses. Ryu et al., (2005, 2007) also evaluated a nitrogen content prediction model using airborne hyperspectral remote sensing at the panicle initiation and heading stage via MLR and PLSR. However, these models were mainly established based on the data of the mixed vegetation stages and/or the fixed vegetation stage with a single year data. Moreover, the characteristics of vegetation growth are easily influenced by the differences in phonological stages, environmental conditions, location and cultural practices (Thenkabail et al., 2000; Ryu et al., 2009).

In this study, airborne hyperspectral remote sensing was applied to analyze the nitrogen content of rice at the heading stage using three years of data. The objectives of this research were: (1) to investigate the vegetation growth of rice at the heading stage; (2) to establish a nitrogen content prediction model using any combination of the three-year data via MLR and PLSR analysis; (3) to verify such models using the remaining data; and (4) to establish a general-purpose prediction model for nitrogen contents at the heading stage. 


\section{Materials and methods}

\subsection{Experimental field and management}

A test field $(0.5$ ha with $50 \mathrm{~m} \times 100 \mathrm{~m})$ in the Takatsuki Experimental Farm of the Graduate School of Agriculture Kyoto University in Takatsuki City, Osaka Prefecture, Japan $\left(135^{\circ} 38^{\prime} \mathrm{E}, 34^{\circ} 51^{\prime} \mathrm{N}, 10 \mathrm{~m}\right.$ above sea level) was used for the experiments. The test crop was Oryza sativa L., cv. HINO-HIKARI and the soil of field was classified as Gray Lowland soil (Yanai et al., 2000). Over three decades, the average annual temperature, amount of rainfall and annual sunshine hours were $15.5^{\circ} \mathrm{C}, 1362 \mathrm{~mm}$, and 1893 hours (JMA, 2007).

Pre-germinated seeds were sown on seedling trays and 29-31-day-old seedlings were transplanted into the field at space intervals of $0.30 \mathrm{~m} \times 0.33 \mathrm{~m}$ (Inamura et al., 2003). Amounts of nitrogen and potassium fertilizer $\left(17 \% \mathrm{~N}\right.$ and $17 \% \mathrm{~K}_{2} \mathrm{O}$, NK fertilizer) were applied in the range $0-85 \mathrm{kgha}^{-1}$ for each plot ( $5 \mathrm{~m} \times 10 \mathrm{~m}$ with 100 plots) as the basal dressing and topdressing. In the case of phosphorus $\left(17.5 \% \mathrm{P}_{2} \mathrm{O}_{5}\right), 30 \mathrm{kgha}^{-1}$ of the fertilizer was also applied uniformly as a basal dressing.

\subsection{Hyperspectral remote sensing}

Hyperspectral Images (Pasco Co., Ltd., Tokyo, Japan) were taken around eleven o'clock with the airborne hyperspectral sensor, AISA Eagle (Specim, Oulu, Finland) on $26^{\text {th }}$ August 2004, $3^{\text {rd }}$ September 2005, and $4^{\text {th }}$ September 2006. The ground spatial resolution was $2.25 \mathrm{~m}^{2}$ with an altitude of $1400 \mathrm{~m}$ (Hache et al. 2005). The grey reflectance panels were set on the sides of the field and the reflectance of each plot $\left(50 \mathrm{~m}^{2}\right)$ was calculated using not the total area of each plot (18 pixels with $40.5 \mathrm{~m}^{2}$ ) but the inner part (4 pixels with $9 \mathrm{~m}^{2}$ ). Using the Environment for Visualizing Images software, ENVI version 4.2 (ITT Visual Information Solutions, Boulder, USA), reflectance of rice plants was calculated by dividing the radiance of each plot by the radiance of the reflectance panels (Ryu et al., 2009).

\subsection{Measurement of vegetation data}

Vegetation data at the heading stage were quantified at forty plots with dry mass, nitrogen concentration and nitrogen content. Each plot consisted of two sub-sampling points and four rice plants at each sub-sampling point were picked without their roots. The samples were well mixed and partitioned into two parts as one-quarter and three-quarters. The one-quarter sample was separated into leaves, autumn leaves, stems and shoots to calculate their ratio (Ryu et al., 2010a). Both sub-samples were dried at $80^{\circ} \mathrm{C}$ for more than 72 hours in a ventilated oven and then weighed (Nakano and Morita, 2008). The dry mass of leaves, autumn leaves, stems and shoots for the three-quarters was calculated using the ratio of them from the one-quarter. The nitrogen concentration for the leaves and stems of one-quarter samples was measured three times using an NC analyzer, NC-900 (Sumica Bunseki Center Co., Ltd., Tokyo, Japan). 
The nitrogen content was calculated as the product of the dry mass per unit area and the mean of nitrogen concentration. Vegetation data for each plot was calculated from the average of two sets of sub-sampled data.

\subsection{Statistical analysis}

Descriptive statistics were calculated over the three years of vegetation data and reflectance. MLR analysis was performed using the step-wise method with SPSS version 13 (SPSS Inc., Chicago, USA). PLSR analysis was also performed using the full-cross validation method with Unscrambler version 9.6 (CAMO software AS, Oslo, Norway). Each model that was established by MLR and PLSR analysis was validated by the other years' data to identify differences between models and to check the possibility of a general-purpose prediction model. The precision of the model and validated model was quantified with the coefficient of determination $\left(\mathrm{R}^{2}\right)$ and the root mean squared error (RMSE) and the relative error (RE), as shown in Eq. (1) and Eq. (2) (Yi et al., 2007).

$$
\begin{gathered}
R M S E=\sqrt{\frac{\sum_{i=1}^{n}\left(\hat{y}_{i}-y\right)^{2}}{n}} \\
R E=\frac{100}{\bar{y}} \sqrt{\frac{\sum_{i=1}^{n}\left(\hat{y}_{i}-y\right)^{2}}{n}}
\end{gathered}
$$

where $\hat{y}_{i}$ and $y_{i}$ are the estimated and measured value of the $i$ th sample; $n$ is the number of samples; $\bar{y}$ is the average of measured value.

\section{Results and discussion}

\subsection{Field management}

Crop managements and weather conditions from seedling to sampling at the heading stage over three years are shown in Table 1 . The sampling date at the heading stage in 2004 was different compared with that in 2005 and 2006. Nevertheless as heading date of HINO-HIKARI in this region was generally in the late August (Urata and Nishigaki, 2001), weather conditions for remote sensing were not acceptable in 2005 and 2006. Moreover, although the accumulated vegetation day-period in 2005 and 2006 was longer than that in 2004, the accumulated daily radiation from transplanting to sampling in 2005 and 2006 was less than $70 \%$ of that in 2004 .

The weather conditions from transplanting to heading stage were compared (Fig. 1) because the amount of nitrogen accumulated by rice plants increases depending on the temperature and radiation intensity (Ta and Ohira, 1982; Angus et al., 1990). 
Table 1 Crop management and weather conditions at the test field from 2004 to 2006.

\begin{tabular}{llll}
\hline Management date & \multicolumn{1}{c}{2004} & \multicolumn{1}{c}{2005} & \multicolumn{1}{c}{2006} \\
\hline Seedling & 14 May & 17 May & 17 May \\
Basal dressing & 4 June & 27 May & 29 May \\
Transplanting & 14 June & 15 June & 15 June \\
Sampling at the panicle initiation stage & 3 August & 5 August & 12 August \\
Topdressing & 10 August & 10 August & 13 August \\
Airborne hyperspectral remote sensing & 26 August & 3 September & 4 September \\
Sampling at the heading stage & 26 August & 5 September & 8 September \\
\hline Weather conditions & 2004 & 2005 & 2006 \\
\hline Accumulated vegetation day-period ${ }^{* a}$ & 72 & 80 & 81 \\
Effective cumulative temperature $\left[{ }^{\circ} \mathrm{C}\right]^{* b}$ & 917 & 996 & 1002 \\
Accumulated daily radiation $\left[\mathrm{MJm}^{-2}\right]$ & 1095 & 764 & 759 \\
\hline
\end{tabular}

${ }^{* a}$ Day from transplanting to sampling

${ }^{* b}$ Sum of the daily average temperature minus $15^{\circ} \mathrm{C}$ from transplanting to sampling)

A difference in the accumulated daily radiation (ADR) between 2004 and other years appeared just after the transplanting. A difference in the effective cumulative temperature (ECT) between 2004 and the other years was found at the beginning of July in 2005 and in late June of 2006. This means that the vegetation conditions in 2004 were different from those conditions in other years.

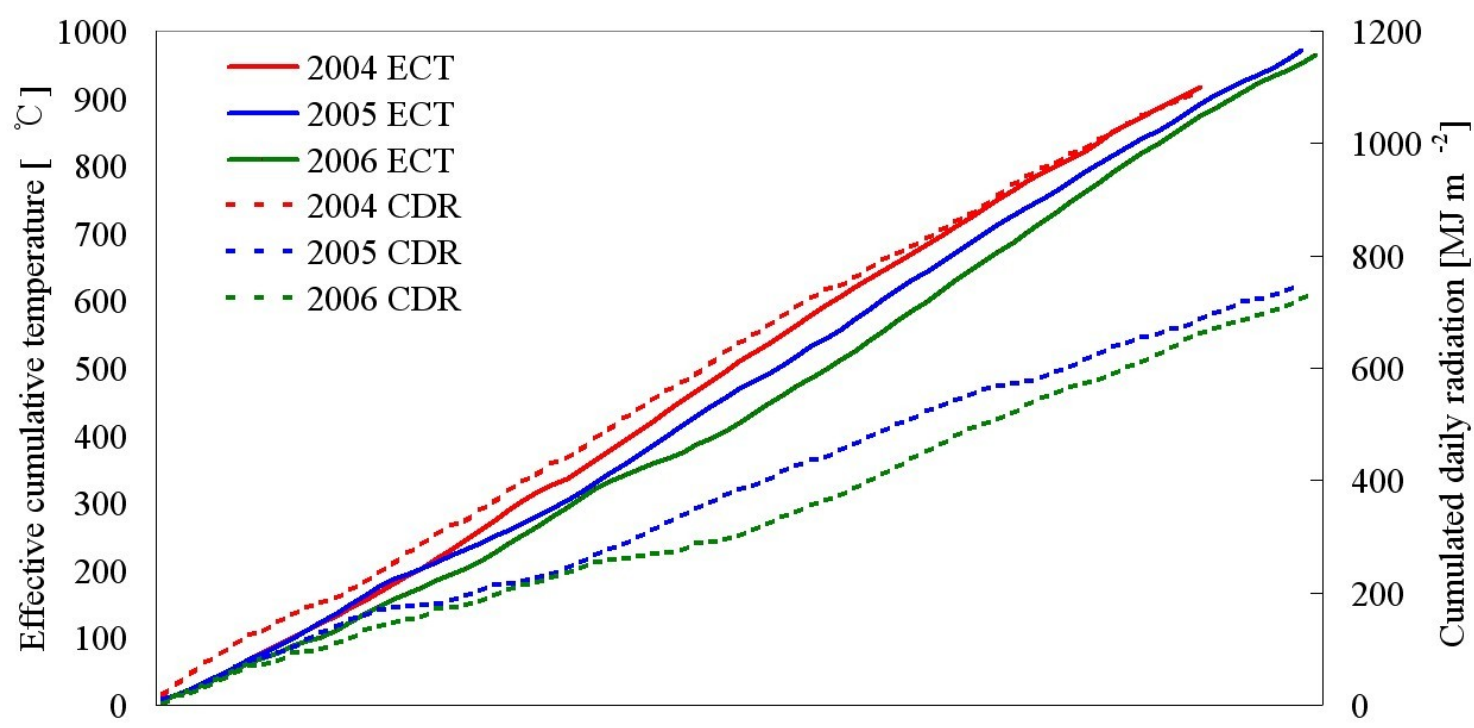

14th 19th 24th 29th 4th 9th 14th 19th 24th 29th 3rd 8th 13th 18th 23rd 28th 2nd Jun Jun Jun Jun Jul Jul Jul Jul Jul Jul Aug Aug Aug Aug Aug Aug Sept Date

Fig. 1 Effective cumulative temperature (ECT) and accumulated daily radiation (ADR) of each year. 


\subsection{Vegetation data}

After the hyperspectral airborne images were taken, the vegetation data at the heading stage were quantified on $26^{\text {th }}$ August in 2004, $5^{\text {th }}$ September in 2005 and $8^{\text {th }}$ September in 2006, as shown in Table 1. Although the dry mass of shoots in 2004 was less those one half of that in 2005 and 2006, the dry mass of leaves in 2004 was around twice those in 2005 and 2006 (Table 2). The difference in the dry mass of shoots might be influenced by the difference in the vegetation date from transplanting to sampling. Moreover, the days from emergence to heading might have been prolonged because of comparatively lower temperatures in 2005 and 2006 (Yoshida et al., 2008). The difference in the dry mass of leaves might also have been influenced by weather conditions because the reduction of daily radiation from panicle initiation to anthesis drastically affected above ground dry mass production (Yoshida and Parao, 1976). The ratio of dry mass in leaves to dry mass in autumn leaves was $6.1 \%$ in $2004,11.7 \%$ in 2005 and $32.0 \%$ in 2006 . The reason that the ratio in 2006 was higher than that in other years might reflect the influence of late remote sensing in 2006. Although the nitrogen concentration of the stems was different among three years data, that for the leaves was significantly different between 2005 and the other years. The nitrogen content of leaves in 2004 was similar than the total nitrogen content in 2005 and around one and half times the total nitrogen in 2006. Although the nitrogen content of shoots was not included in the total, dry mass and nitrogen content of leaves and stems in 2006 was lower than not only those in 2004 but also those in 2005 . This might reflect the influence of weather conditions that indicate lower accumulated temperature and daily radiation (Islam and Morison, 1992) for 2006, as shown in Fig. 1 and Table 1. It might be necessary to measure the nitrogen concentration of shoots to predict accurately the amount of nitrogen content at the heading stage.

Table 2 Descriptive statistics for vegetation data on rice at the heading stage from 2004 to 2006.

\begin{tabular}{lllll}
\hline Years & & 2004 & 2005 & 2006 \\
$\mathrm{n}$ (Sampling date) & & $40(26$ August $)$ & 40 (5 September) & 38 (8 September) \\
\hline \multirow{2}{*}{ Dry mass $\left[\mathrm{g} \mathrm{m}^{-2}\right]$} & Shoots & $123 \pm 17.6^{\mathrm{a}}$ & $264 \pm 21.7^{\mathrm{b}}$ & $300 \pm 41.0^{\mathrm{c}}$ \\
& Autumn leaves & $33.6 \pm 18.0^{\mathrm{a}}$ & $33.1 \pm 18.0^{\mathrm{a}}$ & $72.9 \pm 16.5^{\mathrm{b}}$ \\
& Stems & $651 \pm 62.7^{\mathrm{a}}$ & $569 \pm 43.6^{\mathrm{b}}$ & $443 \pm 67.4^{\mathrm{c}}$ \\
& Leaves & $553 \pm 53.9^{\mathrm{a}}$ & $284 \pm 23.2^{\mathrm{b}}$ & $226 \pm 31.7^{\mathrm{c}}$ \\
\hline \multirow{2}{*}{ Nitrogen concentration [\%] $]$} & Stems & $0.53 \pm 0.08^{\mathrm{a}}$ & $0.67 \pm 0.09^{\mathrm{b}}$ & $0.47 \pm 0.05^{\mathrm{c}}$ \\
& Leaves & $1.86 \pm 0.22^{\mathrm{a}}$ & $2.28 \pm 0.17^{\mathrm{b}}$ & $1.85 \pm 0.18^{\mathrm{a}}$ \\
\hline \multirow{2}{*}{ Nitrogen content $\left[\mathrm{g} \mathrm{m}^{-2}\right]$} & Stems & $3.43 \pm 0.66^{\mathrm{a}}$ & $3.80 \pm 0.54^{\mathrm{b}}$ & $2.09 \pm 0.42^{\mathrm{c}}$ \\
& Leaves & $10.3 \pm 1.75^{\mathrm{a}}$ & $6.47 \pm 0.81^{\mathrm{b}}$ & $4.19 \pm 0.84^{\mathrm{c}}$ \\
\hline & Total & $13.7 \pm 2.39^{\mathrm{a}}$ & $10.3 \pm 1.32^{\mathrm{b}}$ & $6.28 \pm 1.13^{\mathrm{c}}$ \\
\hline
\end{tabular}

Mean \pm Standard deviation

$(a, b, c)$ The same letters are not significantly different at $1 \%$ level 


\subsection{Analysis of the hyperspectral reflectance}

The hyperspectral reflectance of rice plants at the heading stage was similar over three years (Fig. 2). The reflectance increased in the near blue $(450 \mathrm{~nm})$, green $(550 \mathrm{~nm})$ and near infra-red (NIR) region and the increased pattern of reflectance in the heading stage was similar to that in the panicle initiation stage (Ryu et al., 2009). The reflectance in the visible region (from $400 \mathrm{~nm}$ to $700 \mathrm{~nm}$ ) in 2005 was higher than that in the other years. This difference may be influenced by how many plots were already sampled at the panicle initiation stage. There were eighteen plots in 2004, thirty plots in 2005 and ten plots in 2006. Although the vegetation was increased from the panicle initiation to heading stages, there was a difference in the sampled area $\left(0.79 \mathrm{~m}^{2}\right.$ for each plot $)$ as $14.26 \mathrm{~m}^{2}$ in $2004,23.76 \mathrm{~m}^{2}$ in 2005 and $7.92 \mathrm{~m}^{2}$ in 2006 . One of the reasons that the reflectance in visible region in 2005 increased comparing with the other years might be influenced by the difference in the soil background (Kimura et al., 2004). The other reason might be due to the nitrogen concentration of leaves and stems in 2005, as shown in Table 2. As the increase of chlorophyll concentration causes increased reflectance in the visible regions and the movement of the red edge to longer wavelengths (Rock et al., 1988; Demetriades-shad et al., 1990), the position of the red edge in 2005 (around 720nm) was different from that in others (around 700nm). Therefore, not only the difference in the number of the sampled plots at the panicle initiation stage but also that in the nitrogen concentration might be simultaneously affected by the reflectance at the heading stage in 2005 .

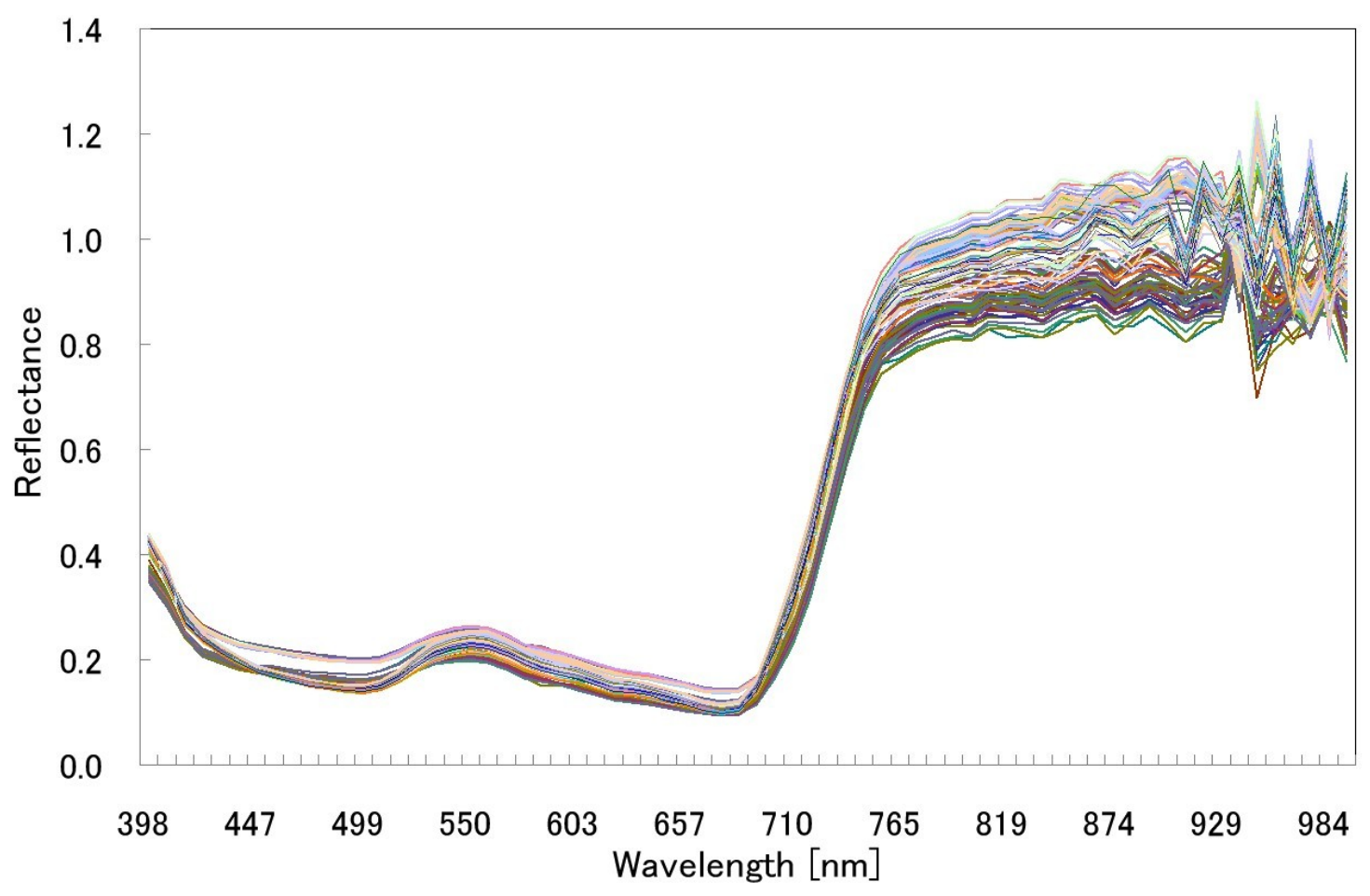

Fig. 2 Hyperspectral reflectance of rice plants at the heading stage for three years. 


\subsection{Multiple linear regression (MLR)}

\subsubsection{MLR modeling}

MLR analysis with the stepwise method was calculated using the reflectance and the measured nitrogen contents (Table 3 ).

Table 3 Results of the MLR analysis with stepwise method using any combination of the three-year data.

\begin{tabular}{|c|c|c|c|c|c|c|}
\hline & \multicolumn{2}{|c|}{$2004(n=40)$} & \multicolumn{2}{|c|}{$2005(n=40)$} & \multicolumn{2}{|c|}{$2006(n=38)$} \\
\hline$\overline{R^{2}\left(\operatorname{Adj} R^{2}\right)}$ & \multicolumn{2}{|c|}{$0.510(0.483)$} & \multicolumn{2}{|c|}{$0.742(0.704)$} & \multicolumn{2}{|c|}{$0.691(0.673)$} \\
\hline RMSE & \multicolumn{2}{|l|}{3.081} & \multicolumn{2}{|c|}{0.660} & \multicolumn{2}{|c|}{0.621} \\
\hline $\mathrm{RE}$ & \multicolumn{2}{|l|}{22.47} & \multicolumn{2}{|c|}{6.429} & \multicolumn{2}{|c|}{9.893} \\
\hline Constant & \multicolumn{2}{|l|}{18.37} & \multicolumn{2}{|c|}{-67.13} & \multicolumn{2}{|c|}{3.617} \\
\hline \multirow[t]{5}{*}{ Variables } & $\mathrm{R}_{710}$ & $-91.97(-0.720)^{* a}$ & $\mathrm{R}_{719}$ & $-86.85(-0.799)$ & $\mathrm{R}_{719}$ & $-50.11(-1.074)$ \\
\hline & \multirow[t]{4}{*}{$\mathrm{R}_{984}$} & $17.20(0.330)$ & $\mathrm{R}_{828}$ & $42.12(0.595)$ & \multirow[t]{4}{*}{$\mathrm{R}_{422}$} & \multirow[t]{4}{*}{$98.67(0.461)$} \\
\hline & & & $\mathrm{R}_{481}$ & $1466(2.871)$ & & \\
\hline & & & $\mathrm{R}_{473}$ & $-1481(-2.942)$ & & \\
\hline & & & $\mathrm{R}_{414}$ & $263.8(0.560)$ & & \\
\hline
\end{tabular}

FCV

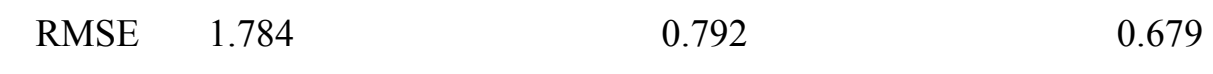

\begin{tabular}{lllll} 
RE & 13.01 & 7.710 & \multicolumn{2}{c}{10.81} \\
\hline & $2004-2005$ & $2004-2006$ & $2005-2006$ & Total
\end{tabular}

\begin{tabular}{lllll} 
& $2004-2005$ & $2004-2006$ & $2005-2006$ & Total \\
\hline$R^{2}\left(\operatorname{Adj} R^{2}\right)$ & $0.700(0.693)$ & $0.941(0.934)$ & $0.893(0.888)$ & $0.901(0.893)$ \\
RMSE & 1.405 & 1.013 & 0.762 & 1.092 \\
RE & 11.72 & 10.04 & 9.153 & 10.76
\end{tabular}

Constant

23.96

$-22.28$

2.240

17.90

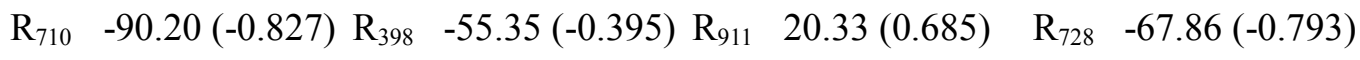

$\begin{array}{lllllllll}\mathrm{R}_{984} & 13.70(0.201) & \mathrm{R}_{473} & 523.9(0.829) & \mathrm{R}_{728} & -45.90(-0.516) & \mathrm{R}_{490} & 247.0(1.669)\end{array}$

$\begin{array}{llllll}\mathrm{R}_{737} & -173.8(-2.130) & \mathrm{R}_{414} & 62.34(0.227) & \mathrm{R}_{993} & 10.27(0.259)\end{array}$

Variables

$\begin{array}{llllll}\mathrm{R}_{819} & 121.7(1.562) & \mathrm{R}_{947} & -7.014(-0.376) & \mathrm{R}_{938} & 5.678(0.116)\end{array}$

$\begin{array}{llll}\mathrm{R}_{728} & 106.1(1.234) & \mathrm{R}_{947} & -8.622(-0.377)\end{array}$

$\mathrm{R}_{684}-297.7(-0.430) \quad \mathrm{R}_{892} \quad 52.01(1.009)$

$\mathrm{R}_{783}-105.8(-1.184) \quad \mathrm{R}_{883}-27.45(-0.619)$

$\begin{array}{llll}\mathrm{R}_{874} & 45.48(0.817) & \mathrm{R}_{439} & -220.7(-1.218)\end{array}$

FCV

$\begin{array}{lllll}\text { RMSE } & 1.470 & 1.152 & 0.815 & 1.198 \\ \text { RE } & 12.26 & 11.41 & 9.790 & 11.80\end{array}$

$\overline{\operatorname{Adj}} R^{2}$, Adjusted $R^{2}$; RMSE, Root mean square of error $\left[\mathrm{gm}^{-2}\right]$; RE, Relative error [\%]; FCV, Fullcross validation.

${ }^{*}$ : Standardized Coefficients 
The accuracy of the single-year model was $\mathrm{R}^{2} \geq 0.673$, RMSE $\leq 0.660 \mathrm{gm}^{-2}$ and $\mathrm{RE} \leq 9.893 \%$, except the 2004 model. The accuracy of the 2004 model was less $\left(\mathrm{R}^{2}=0.483, \mathrm{RMSE}=3.081 \mathrm{gm}^{-2}\right.$ and $\mathrm{RE}=22.47 \%$ ). When the two-year data models were established (2004-2005, 2004-2006 and 20052006), accuracy of models was $\mathrm{R}^{2} \geq 0.888$, RMSE $\leq 1.013 \mathrm{gm}^{-2}$ and $\mathrm{RE} \leq 9.153 \%$, except the 2004-2005 model. One of the reasons that the 2004 and the 2004-2005 models had lower accuracy might be the number of suitable variables and their position. When each model was validated by full-cross validation, the accuracy was $\mathrm{RMSE} \leq 1.784 \mathrm{gm}^{-2}$ and $\mathrm{RE} \leq 13.01 \%$ for the single-year models and RMSE $\leq 1.470 \mathrm{gm}^{-2}$ and $\mathrm{RE} \leq 12.93 \%$ for the multi-year models. When the total model was established using three years data, the accuracy was $\mathrm{R}^{2}=0.893$, $\mathrm{RMSE}=1.092 \mathrm{gm}^{-2}$ and $\mathrm{RE}=10.76 \%$ with eight variables. In the case of the total model, the accuracy for validation was RMSE $=1.198 \mathrm{~g} \mathrm{~m}^{-2}$ and $\mathrm{RE}=11.80 \%$. Although the accuracy of the models was variable, the multi-year model included with the total model might be useful for predicting the nitrogen content at the heading stage. Moreover, the red edge having a sharp order-of-magnitude increase in leaf reflectance between approximately 700 and $750 \mathrm{~nm}$ wavelength (Seager et al., 2005) might be important for estimating the nitrogen content at the heading stage because all models had more than one variable in the red-edge region and fluorescence bands belonging to chlorophyll-a are observed with maxima at 690 and $735 \mathrm{~nm}$ (Lichtenthaler, 1988).

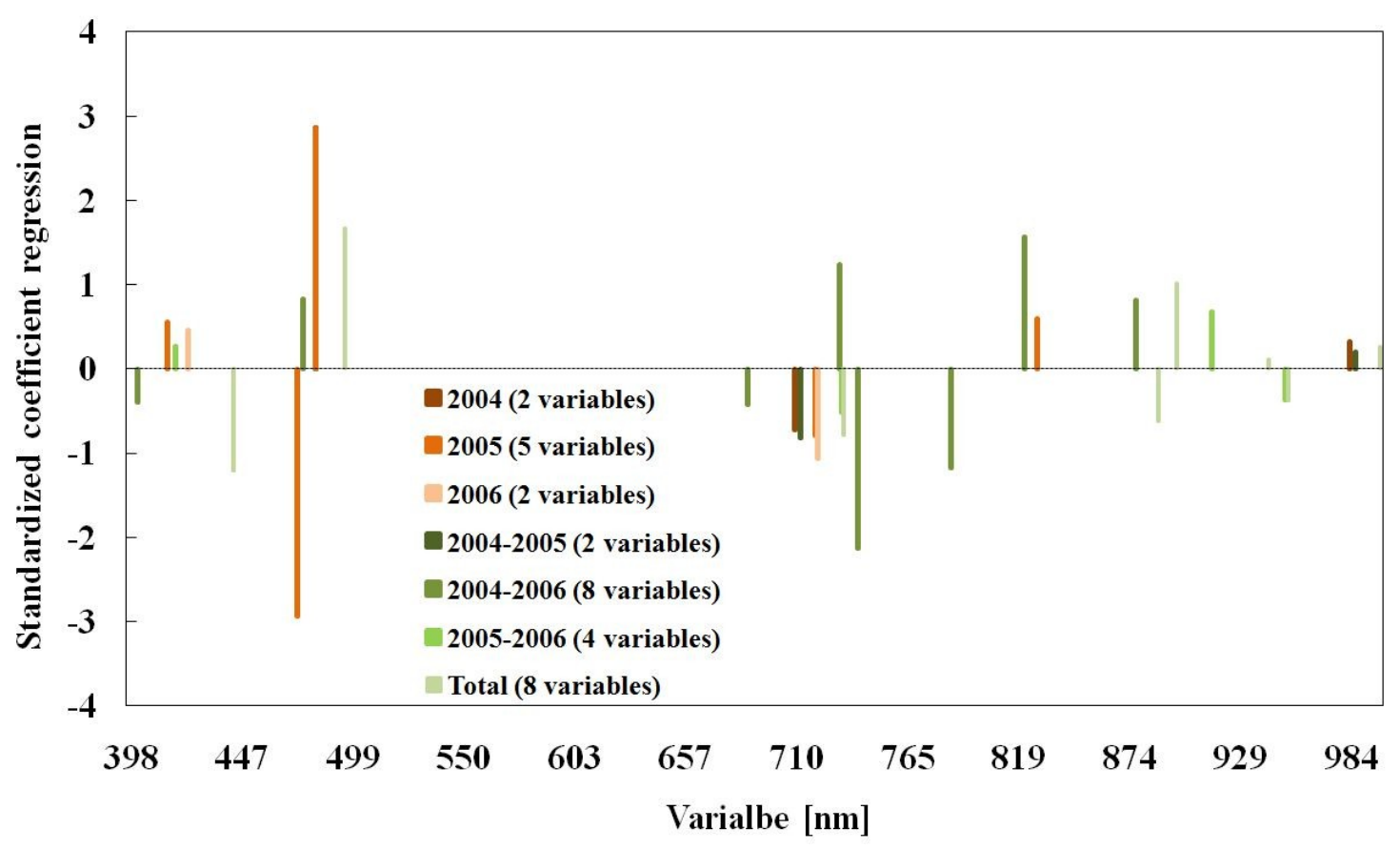

Fig. 3 Comparison of the standardized regression coefficient for each MLR model.

The variables for each MLR model were compared to identify important variables (Fig. 3). The selected variables were centralized in the blue, red-edge regions and widely decentralized in the NIR regions. 
Although the standardized regression coefficients in the NIR regions were mainly in positive values, those in red-edge were in negative values. However, the standardized regression coefficients in the blue regions coexisted in positive and negative values. The origin of blue fluorescence is still under discussion, but evidence is accumulating that associates it with non-photosynthetic parts of the plant tissue including cellular wall components or precursors, skin waxes and vacuolar metabolites (Moya et al., 1992). Moreover, there have been the several reports mentioning the importance of the blue regions in estimating plant growth (Chappelle et al., 1991; Stroppiana et al. 2009).

\subsubsection{Verification of MLR model}

Each MLR model was verified using the other year data (Table 4). When the 2004 model was verified using the nitrogen content in 2005 and 2006, the accuracy was RMSE $\leq 2.63 \mathrm{gm}^{-2}$ and $\mathrm{RE} \leq 25.6 \%$. In the case of the 2005 model, the accuracy decreased as RMSE $\geq 6.59 \mathrm{gm}^{-2}$ and $\mathrm{RE} \geq 105 \%$. When the 2006 model was verified, the accuracy was $\mathrm{RMSE}=7.22 \mathrm{gm}^{-2}$ and $\mathrm{RE}=52.6 \%$ for the data in 2004 and $\mathrm{RMSE}=1.27 \mathrm{gm}^{-2}$ and $\mathrm{RE}=12.3 \%$ for the data in 2005 . One of the reasons that the accuracy of the 2005 model decreased might be due to the difference in the reflectance between 2005 and the other years, as shown in Fig. 2. The reason that the accuracy of the 2006 model decreased for the data in 2004 might be due to the variable in the blue region that was selected as a variable in the 2006 model but not in the 2004 model, as shown in Table 3.

Table 4 Results of the verified error for each MLR model.

\begin{tabular}{|c|c|c|c|c|}
\hline \multirow{2}{*}{ MLR model } & & \multicolumn{3}{|l|}{ Data } \\
\hline & & $2004(40)^{\mathrm{a}}$ & $2005(40)$ & $2006(38)$ \\
\hline \multirow{2}{*}{$2004(2)^{b}$} & $\mathrm{RMSE}^{\mathrm{c}}$ & . & $2.63 \mathrm{gm}^{-2}$ & $1.45 \mathrm{gm}^{-2}$ \\
\hline & $R E^{\mathrm{d}}$ & . & $25.6 \%$ & $23.1 \%$ \\
\hline \multirow{2}{*}{2005 (5) } & RMSE & $16.3 \mathrm{gm}^{-2}$ & . & $6.59 \mathrm{gm}^{-2}$ \\
\hline & $\mathrm{RE}$ & $119 \%$ & . & $105 \%$ \\
\hline \multirow{2}{*}{$2006(2)$} & RMSE & $7.22 \mathrm{gm}^{-2}$ & $1.27 \mathrm{gm}^{-2}$ & . \\
\hline & $\mathrm{RE}$ & $52.6 \%$ & $12.3 \%$ & . \\
\hline \multirow{2}{*}{$2004-2005$ (2) } & RMSE & . & . & $2.58 \mathrm{gm}^{-2}$ \\
\hline & $\mathrm{RE}$ & . & . & $41.1 \%$ \\
\hline \multirow{2}{*}{$2004-2006$ (8) } & RMSE & . & $19.1 \mathrm{gm}^{-2}$ & . \\
\hline & $\mathrm{RE}$ & . & $186 \%$ & . \\
\hline \multirow{2}{*}{$2005-2006(4)$} & RMSE & $6.59 \mathrm{gm}^{-2}$ & . & . \\
\hline & $\mathrm{RE}$ & $48.1 \%$ & . & . \\
\hline
\end{tabular}

\footnotetext{
${ }^{a}$ Number of samples,

${ }^{\mathrm{b}}$ Number of variables,

${ }^{c}$ RMSE mean square of error,

${ }^{\mathrm{d}}$ Relative error.
} 
When the two-year models were verified using the other year data, the accuracy was RMSE $=2.58$ $\mathrm{gm}^{-2}$ and $\mathrm{RE}=41.1 \%$ for the 2004-2005 model, RMSE $=19.1 \mathrm{gm}^{-2}$ and $\mathrm{RE}=186 \%$ for the 2004-2006 model and RMSE $=6.59 \mathrm{gm}^{-2}$ and $\mathrm{RE}=48.1 \%$ for the $2005-2006$ model. The reason that the accuracy of the 2004-2006 model for the nitrogen content in 2005 decreased might also be influenced by the difference in the reflectance between 2005 and the other years. The accuracy of the validated multiyear models was not stable because the accuracy of those models included not only a similarity of selected variables but also a difference of selected variables. Therefore it might be not suitable to predict the nitrogen content at the heading stage by the other year model when the selected variables are not similar to each other.

\subsection{Partial least squares regression (PLSR)}

\subsubsection{PLSR modeling}

PLSR analysis with full-cross validation was calculated using the reflectance and the measured nitrogen contents (Table 5). The accuracy of the single-year model was $\mathrm{R}^{2} \geq 0.762$, RMSE $\leq 1.042 \mathrm{gm}^{-2}$ and $\mathrm{RE} \leq 6.682 \%$ for the calibration.

Table 5 Results of the PLSR analysis with full-cross validation using any combination of the threeyear data.

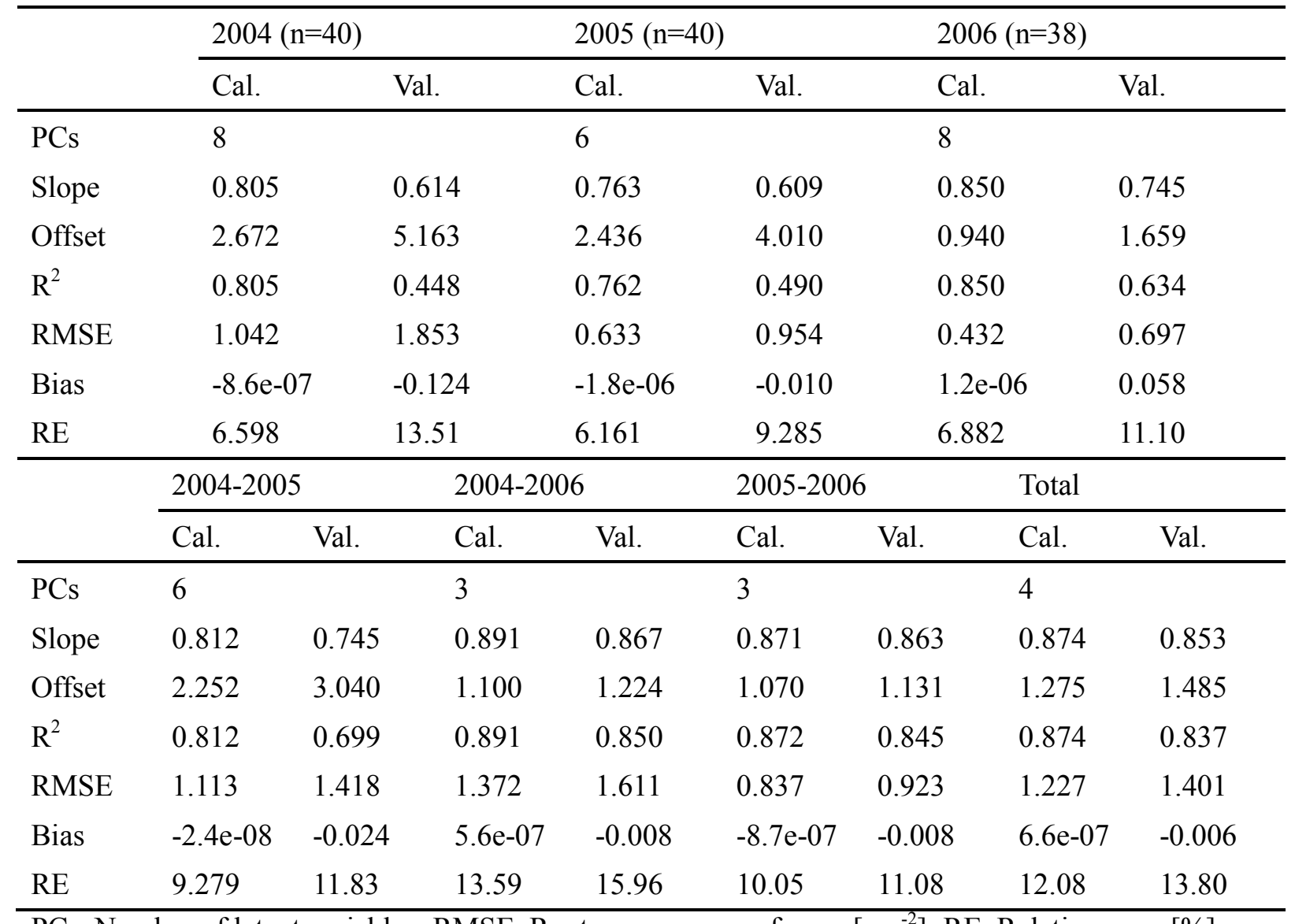

PCs, Number of latent variables; RMSE, Root mean square of error $\left[\mathrm{gm}^{-2}\right]$; RE, Relative error [\%]. 
However, the accuracy of the validation model was $\mathrm{R}^{2} \geq 0.448$, RMSE $\leq 1.853 \mathrm{gm}^{-2}$ and $\mathrm{RE} \leq 13.51 \%$. These differences in the accuracy between the calibration and validation models might be influenced by the over-fitting of the calibration model. When the two-year data models were established, the accuracy of the calibration models was $\mathrm{R}^{2} \geq 0.812$, RMSE $\leq 1.372 \mathrm{gm}^{-2}$ and $\mathrm{RE} \leq 13.59 \%$. The accuracy of the validation model was $\mathrm{R}^{2} \geq 0.845$, RMSE $\leq 1.611 \mathrm{gm}^{-2}$ and $\mathrm{RE} \leq 15.96 \%$, except the 2004-2005 model. One of the reasons that the 2004-2005 model had lower accuracy might be due to the slope and offset between calibration and validation. It might also be due to the difference and similarity of nitrogen content between 2004 and 2005 because a non-linear relationship between reflectance and nitrogen content might exist (Valkan Bilgili et al., 2010). When the total model was established using three years data, the accuracy was $\mathrm{R}^{2}=0.837$, $\mathrm{RMSE}=1.401 \mathrm{gm}^{-2}$ and $\mathrm{RE}=13.80 \%$ with four latent variables. Although the accuracy of the PLSR models was variable, the multi-year model included with the total model might be useful to predict the nitrogen content at the heading stage, the same as the result of the MLR analysis.

The regression coefficients for each PLSR model were compared to identify important variables (Fig. 4). The regression coefficients in the visible region for the single-year models were variable compared with those for the multi-year models, except the 2004-2005 model which had a peak in the green and red regions. The regression coefficient for the 2004 model had a different tendency compared to that of the others. This might be due to the difference in the vegetation growth, as shown in Table 2. The red-edge region was also selected as an important variable (Curran et al., 1991) as shown in the results of MLR analysis. However, the regression coefficients in the red-edge region for the multi-year models were decreased compared with those for the single-year models.

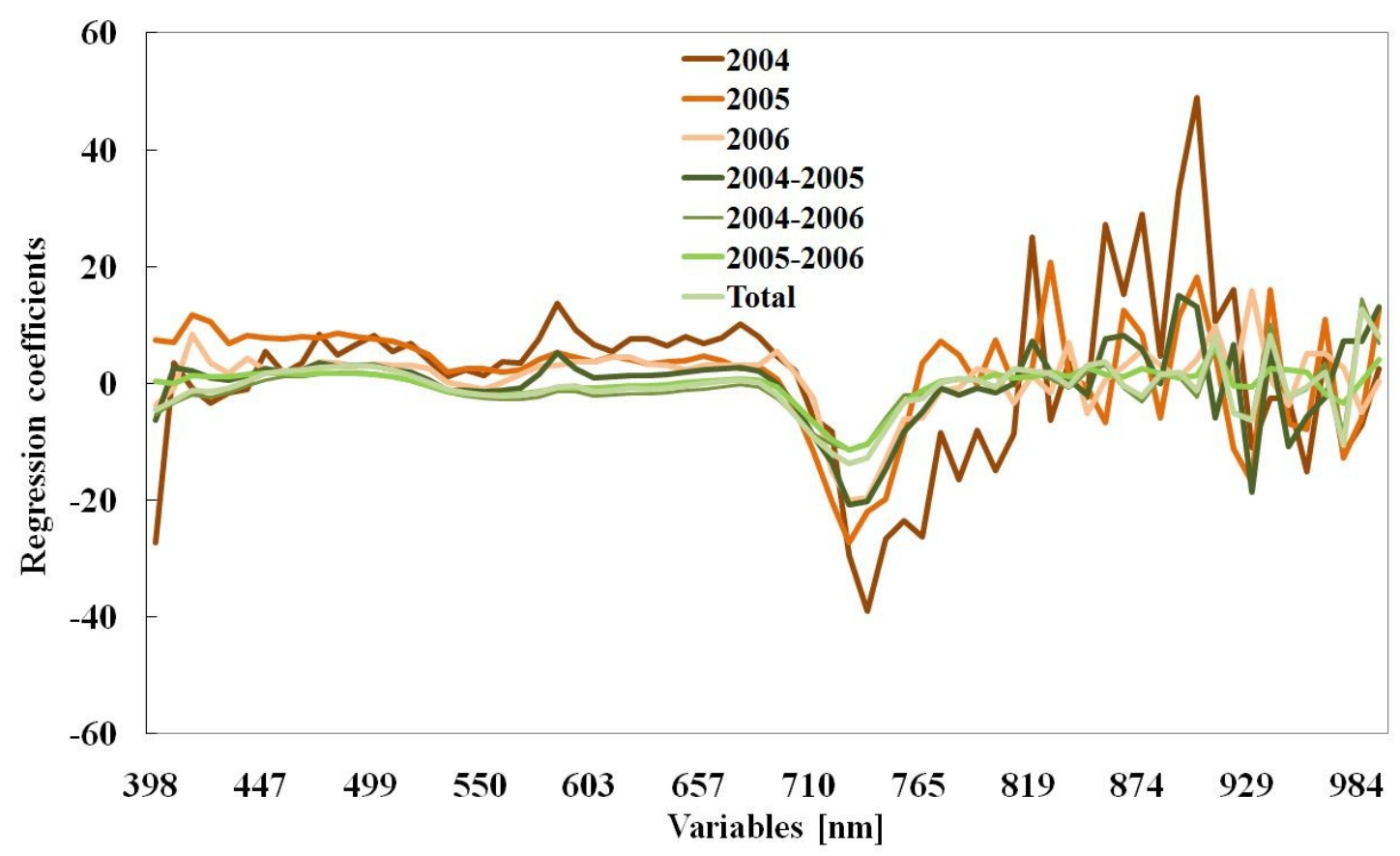

Fig. 4. Comparison of the regression coefficients for each PLSR model. 
Moreover, the patterns of the regression coefficients for the multi-year models depending on the reflectance were similar, except the 2004-2005 model. Therefore, to what extent each variable can explain the reflectance and nitrogen was investigated.

The percentages of the explained $\mathrm{X}$ and $\mathrm{Y}$ variables were compared depending on the number of latent variables (Table 6). It was possible to explain more than $86 \%$ of $\mathrm{X}$ variables (the hyperspectral reflectance) and more than $77 \%$ of $\mathrm{Y}$ variables (the nitrogen content). However, in the case of the multi-year models, it was possible to explain more than $86 \%$ of $X$ variables and $81 \%$ of $Y$ variables. Moreover, it was possible to explain more than $86 \%$ of $X$ variables and $74 \%$ of $Y$ variables with only three latent variables. This means that three latent variables from hyperspectral reflectance could explain at least $74 \%$ of the nitrogen content of rice plants at the heading stage (Takahashi et al., 2000). Although the first latent variable in the 2005 model explained only 8\% of the hyperspectral reflectance, it explained $52 \%$ of the nitrogen content at the heading stage. This might be due to the difference in the reflectance between 2005 and the other years, as mentioned before.

Table 6 Percentages of the explained $\mathrm{X}$ and $\mathrm{Y}$ variables depending on the number of latent variables

\begin{tabular}{|c|c|c|c|c|c|c|c|c|c|c|c|}
\hline & & PC1 & $\mathrm{PC} 2$ & PC3 & PC4 & PC5 & PC6 & PC7 & PC8 & Total & PC1-PC3 \\
\hline \multirow{2}{*}{2004} & $\mathrm{x}$ & 43 & 32 & 8 & 4 & 4 & 1 & 3 & 1 & 96 & 83 \\
\hline & $\mathrm{y}$ & 30 & 22 & 7 & 7 & 5 & 7 & 1 & 2 & 81 & 59 \\
\hline \multirow{2}{*}{2005} & $\mathrm{x}$ & 8 & 58 & 11 & 2 & 4 & 4 & & & 87 & 77 \\
\hline & $\mathrm{y}$ & 52 & 3 & 6 & 12 & 3 & 1 & & & 77 & 61 \\
\hline \multirow{2}{*}{2006} & $\mathrm{x}$ & 35 & 22 & 13 & 6 & 7 & 3 & 5 & 2 & 93 & 70 \\
\hline & $\mathrm{y}$ & 40 & 20 & 11 & 4 & 3 & 4 & 1 & 2 & 85 & 71 \\
\hline \multirow{2}{*}{$2004-2005$} & $\mathrm{x}$ & 92 & 3 & 2 & 1 & 1 & 0 & & & 99 & 97 \\
\hline & $\mathrm{y}$ & 42 & 24 & 8 & 3 & 3 & 1 & & & 81 & 74 \\
\hline \multirow{2}{*}{ 2004-2006 } & $\mathrm{x}$ & 85 & 5 & 2 & & & & & & 92 & 92 \\
\hline & $\mathrm{x}$ & 67 & 19 & 3 & & & & & & 89 & 89 \\
\hline \multirow{2}{*}{$2005-2006$} & $\mathrm{x}$ & 77 & 3 & 6 & & & & & & 86 & 86 \\
\hline & $\mathrm{x}$ & 74 & 11 & 3 & & & & & & 88 & 88 \\
\hline \multirow{2}{*}{ Total } & $\mathrm{x}$ & 66 & 25 & 3 & 1 & & & & & 95 & 94 \\
\hline & $\mathrm{x}$ & 47 & 22 & 16 & 4 & & & & & 89 & 85 \\
\hline
\end{tabular}

PCs, latent variables in order.

Therefore, the loading weights of latent variables depending on the reflectance for each PLSR model were compared (Fig. 5). The number of latent variables was compared up to the third one, because the latent variables of the 2004-2006 and 2005-2006 models had only three latent variables. 
In the NIR region, there was a difference in the loading weights of the first latent variable between the single-year models and the multi-year models, except the 2005-2006 model (Fig. 5a). Moreover, the loading weights of the 2004-2006 and the total models were similar from visible to NIR regions.

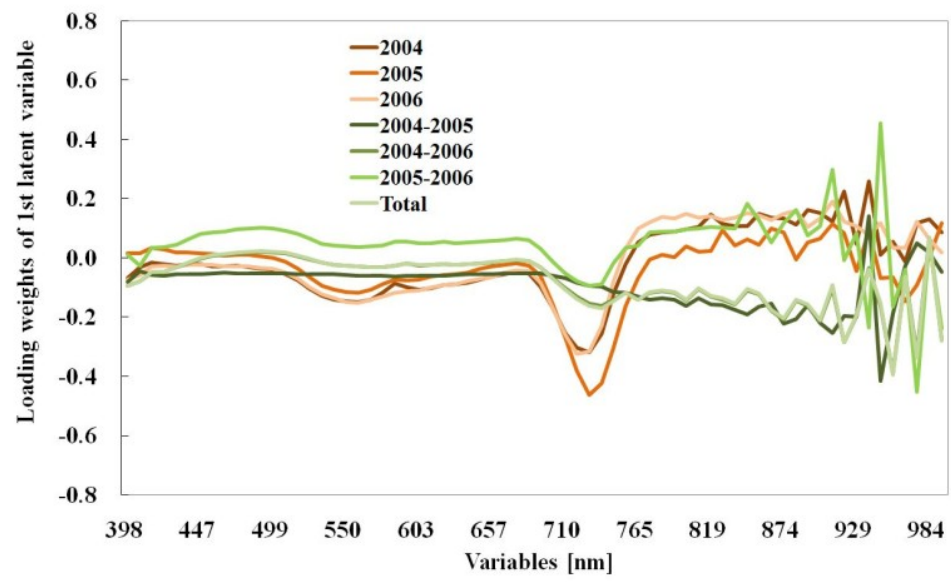

(a) Loading weights of $1^{\text {st }}$ latent variable

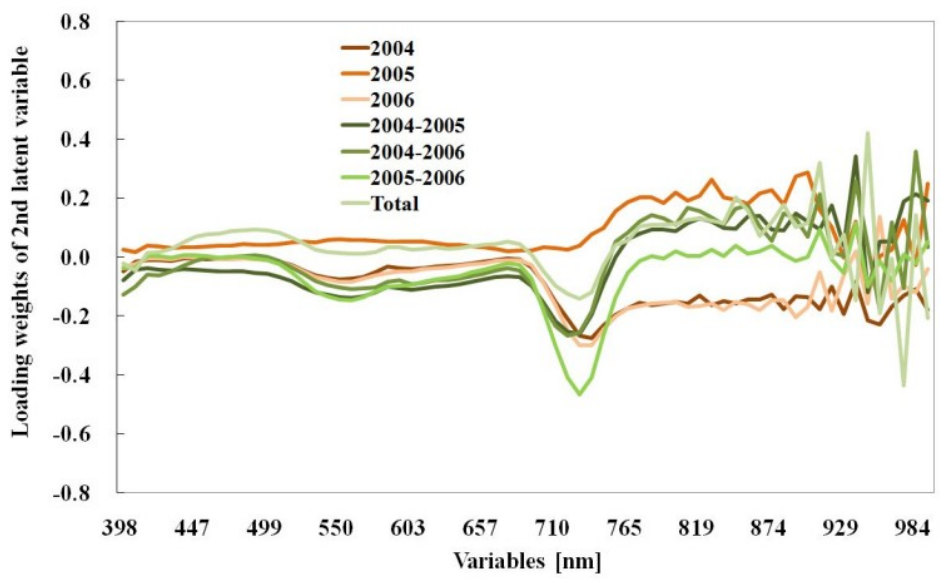

(b) Loading weights of $2^{\text {nd }}$ latent variable

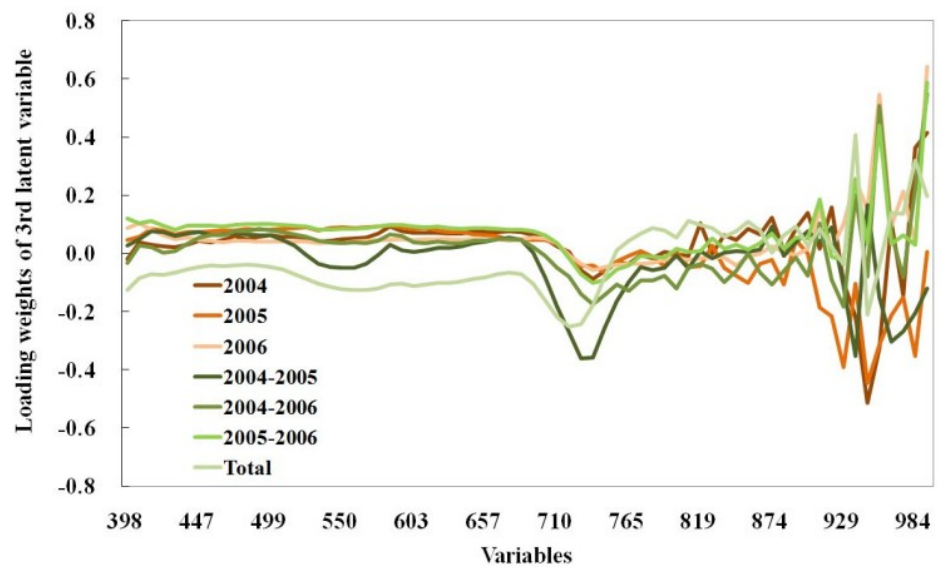

(c) Loading weights of $3^{\text {rd }}$ latent variable

Fig. 5 Comparison of the loading weights for each PLSR model depending on the main latent variables. 
In the case of the second latent variable (Fig. 5b), there was a difference in the loading weights in the NIR region between the single-year and the multi-year models, except the 2005 model. However, the loading weights of the third latent variable in the NIR region were not different compared with that for the first and second latent variables. There was less variation of loading weights in the visible and red-edge regions than that in the NIR region. The variation of loading weights was more changeable from $900 \mathrm{~nm}$ to $1000 \mathrm{~nm}$, the same as the regression coefficients in Fig. 4. The variation was evidently influenced by the water vapor absorption (Green et al., 1998). The similarities and differences of loading weights for each model depending on hyperspectral reflectance might have affected the regression coefficients and the accuracy of each model.

\subsubsection{Verification of PLSR model}

Each PLSR model was verified using the other year data (Table 7). When the 2004 model was verified using the data in 2005 and 2006, the accuracy was RMSE $\geq 6.75 \mathrm{gm}^{-2}$ and $\mathrm{RE} \geq 107 \%$. In the case of the 2005 model, the accuracy was RMSE $\geq 6.30 \mathrm{gm}^{-2}$ and $\mathrm{RE} \geq 75.6 \%$. When the 2006 model was verified using the other year data, the accuracy was RMSE $=8.52 \mathrm{gm}^{-2}$ and $\mathrm{RE}=62.2 \%$ for the 2004 data, and $\mathrm{RMSE}=1.69 \mathrm{gm}^{-2}$ and $\mathrm{RE}=16.5 \%$ for the 2005 data. One of the reasons for the decrease in the accuracy of the single-year models might be due to the difference in the regression coefficient, as shown in Fig. 4.

Table 7 Results of the verified error for each PLSR model.

\begin{tabular}{|c|c|c|c|c|}
\hline \multirow{2}{*}{ PLSR model } & & \multicolumn{3}{|l|}{ Data } \\
\hline & & $2004(40)^{\mathrm{a}}$ & $2005(40)$ & $2006(38)$ \\
\hline \multirow{2}{*}{$2004(8)^{b}$} & RMSE $^{\mathrm{c}}$ & . & $20.8 \mathrm{gm}^{-2}$ & $6.75 \mathrm{gm}^{-2}$ \\
\hline & $\mathrm{RE}^{\mathrm{d}}$ & . & $203 \%$ & $107 \%$ \\
\hline \multirow{2}{*}{$2005(6)$} & RMSE & $10.4 \mathrm{gm}^{-2}$ & . & $6.30 \mathrm{gm}^{-2}$ \\
\hline & $\mathrm{RE}$ & $75.6 \%$ & . & $100 \%$ \\
\hline \multirow{2}{*}{$2006(8)$} & RMSE & $8.52 \mathrm{gm}^{-2}$ & $1.69 \mathrm{gm}^{-2}$ & . \\
\hline & $\mathrm{RE}$ & $62.2 \%$ & $16.5 \%$ & . \\
\hline \multirow{2}{*}{$2004-2005$ (6) } & RMSE & . & . & $6.04 \mathrm{gm}^{-2}$ \\
\hline & $\mathrm{RE}$ & . & . & $96.1 \%$ \\
\hline \multirow{2}{*}{$2004-2006(3)$} & RMSE & . & $2.68 \mathrm{gm}^{-2}$ & . \\
\hline & $\mathrm{RE}$ & . & $26.1 \%$ & . \\
\hline \multirow{2}{*}{$2005-2006(3)$} & RMSE & $6.71 \mathrm{gm}^{-2}$ & . & . \\
\hline & $\mathrm{RE}$ & $48.9 \%$ & . & . \\
\hline
\end{tabular}

\footnotetext{
${ }^{\mathrm{a}}$ Number of samples

${ }^{\mathrm{b}}$ Number of latent variables

${ }^{\mathrm{c}}$ Root mean square of error

${ }^{\mathrm{d}}$ Relative error
} 
Moreover, it was also influenced by the difference in the reflectance and vegetation over three years. When the two-year models were verified using the other year data, the accuracy was RMSE $=6.04$ $\mathrm{gm}^{-2}$ and $\mathrm{RE}=96.1 \%$ for the 2004-2005 model, RMSE $=2.68 \mathrm{gm}^{-2}$ and $\mathrm{RE}=26.1 \%$ for the $2004-2006$ model and RMSE $=6.71 \mathrm{gm}^{-2}$ and $\mathrm{RE}=48.9 \%$ for the 2005-2006 model. Although there was little difference in RMSE between the 2004-2005 and 2005-2006 models, RE for the 2004-2005 model was twice than that for the 2005-2006 model. It might be influenced by the variation of nitrogen content, because the nitrogen content in 2006 showed less variation than that in 2004. As a result of the verification, it might be possible to decrease the error when the model is estimated using the multi-year data.

\subsubsection{Comparison of MLR and PLSR models}

The accuracy of the MLR and PLSR models was compared. There was a different tendency in the important variables between the MLR and PLSR models. Although the important variables were selected in the near blue, red-edge and NIR regions in the MLR models (Fig. 3), there were no important variables in the near blue in the PLSR models, except the 2004 PLSR model (Fig. 4). In the single-year MLR and PLSR models, the accuracy of the verified 2004 model between the MLR (Table 4) and PLSR (Table 7) models had a different tendency even though the accuracy of the other models was similar. The RE of the 2004 PLSR model was more than four times that of the 2004 MLR model. One of the reasons might be the possibility of over-fitting for the 2004 PLSR model, as shown in Table 5. Moreover, the pattern of regression coefficient between 2004 and the other years was different from $700 \mathrm{~nm}$ to $900 \mathrm{~nm}$. This might reflect an influence not of the loading weights from the first to third latent variables but those from the fourth to eighth latent variables, as shown in Fig. 5 and Table 6.

In the case of the multi-year MLR and PLSR models, the nitrogen content in 2006 was overestimated by the 2004-2005 models not only MLR but also PLSR (Fig. 6). However, the nitrogen content in 2005 was overestimated by the 2004-2006 MLR model but underestimated by the 20042006 PLSR model. In the case of the nitrogen content in 2004, it was underestimated by the 20052006 models not only in MLR but also in PLSR. In the 2004-2006 MLR model, the accuracy was not suitable for verifying the nitrogen content in 2005. Although the position of the variables between the 2005 MLR model and the 2004-2006 MLR model was not different, the variables were concentrated in the blue region in the 2005 model but those were in the red-edge and NIR regions in the 20042006 MLR model, as shown in Table 3. The pattern of the regression coefficients between the 20042006 PLSR model and the 2005 PLSR model was different as shown in Fig. 4. This might be due to the difference in the loading weights in not the third latent variable but in the first and second variables as shown in Fig. 5. 

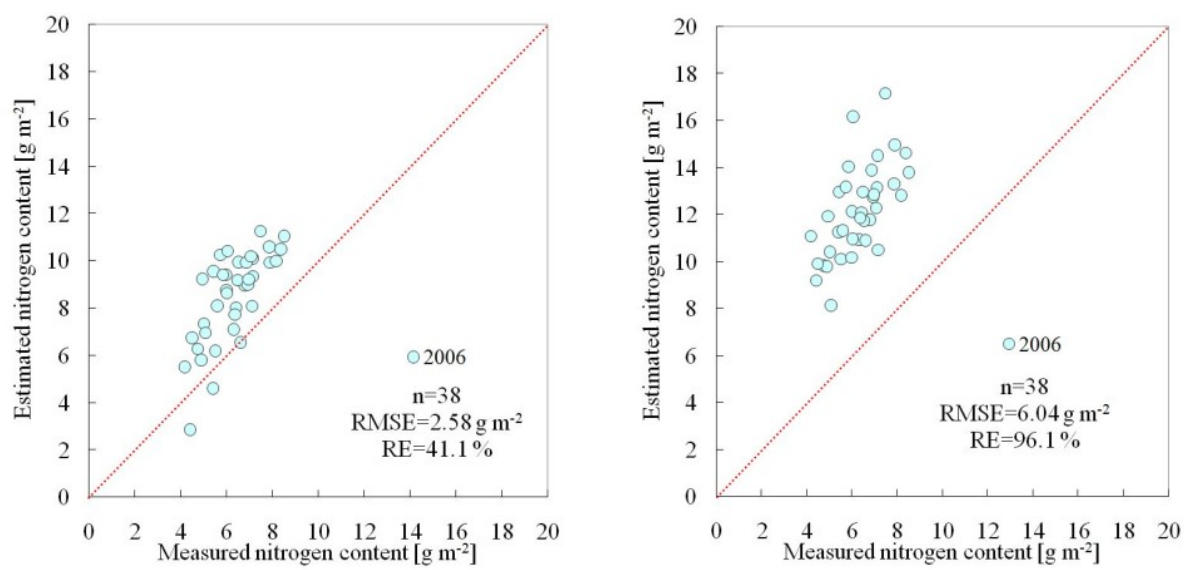

(a) Verified 2006 data using the 2004-2005 model
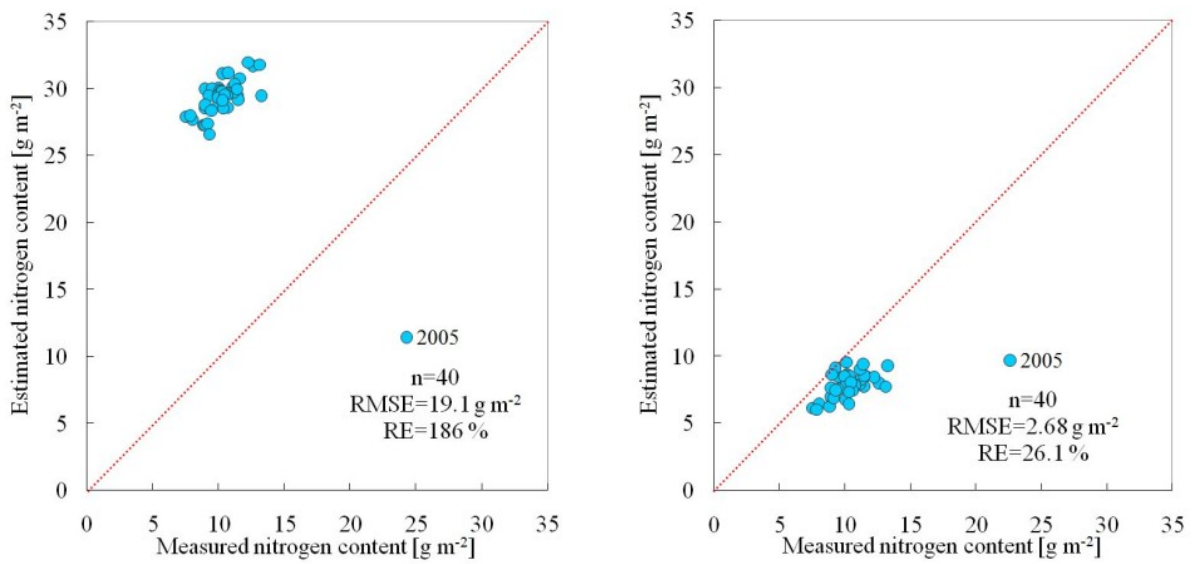

(6) Verified 2005 data using the 2004-2006 model
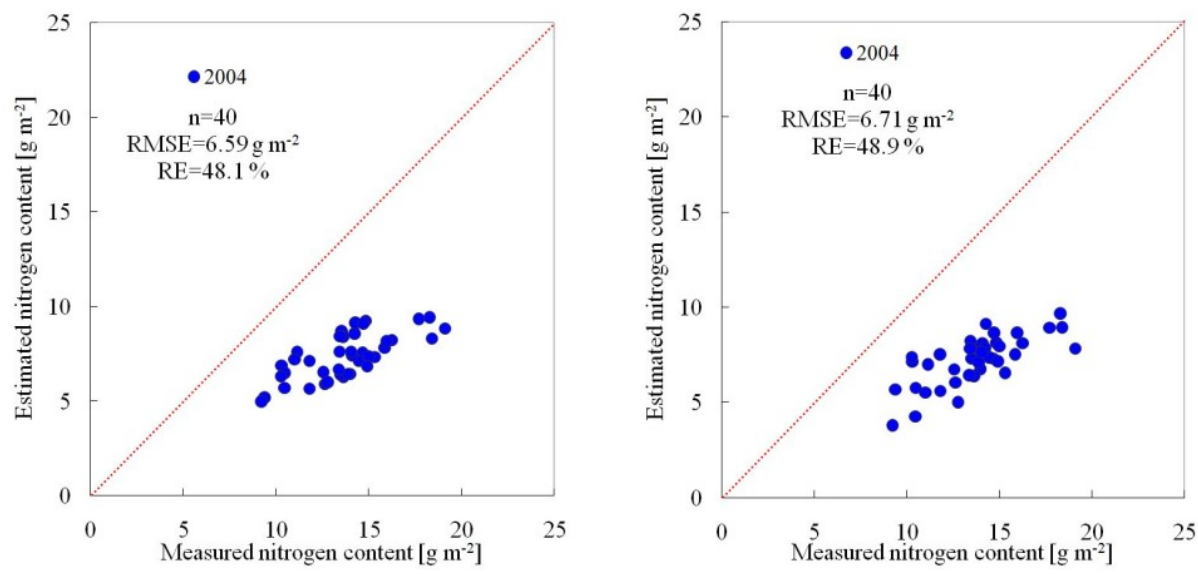

(c) Verified 2004 data using the 2005-2006 model

Fig. 6. Comparison of the error between MLR (left) and PLSR (right) models.

When the single-year MLR models were verified using the other year data, RMSE was from 1.27 $\mathrm{gm}^{-2}$ to $16.3 \mathrm{gm}^{-2}$ and RE was from $12.3 \%$ to $119 \%$. In the case of the single-year PLSR models, RMSE was from $1.69 \mathrm{gm}^{-2}$ to $20.8 \mathrm{gm}^{-2}$ and RE was from $16.5 \%$ to $203 \%$. 
The accuracy of the single-year MLR models was better than that of the single-year PLSR models. When the multi-year MLR models were verified using the other year data, RMSE was from $2.58 \mathrm{gm}^{-2}$ to $19.1 \mathrm{gm}^{-2}$ and RE was from $41.1 \%$ to $186 \%$. In the case of the multi-year PLSR models, RMSE was from $2.68 \mathrm{~g} \mathrm{~m}^{-2}$ to $6.71 \mathrm{~g} \mathrm{~m}^{-2}$ and RE was from $26.1 \%$ to $96.1 \%$. The accuracy of the multi-year PLSR models was better than that of the multi-year MLR models. Therefore, it might be suitable to predict the nitrogen contents at the heading stage using the multi-year PLSR model because PLSR models have more sensitive than MLR models for the inhomogeneous results. However, it might be necessary to accumulate the reflectance and the nitrogen content of rice plants at the heading to increase the accuracy of models.

\subsection{General-purpose prediction model}

The validated total model of MLR and PLSR was compared (Fig. 7). The nitrogen content in 2005 might play an important role; had the 2005 data not existed, the 2004 and 2006 data would have been completely separated into two groups. The accuracy was similar to each other as RMSE $=1.198 \mathrm{gm}^{-2}$, $\mathrm{RE}=11.80 \%$ for the MLR model and RMSE $=1.401 \mathrm{gm}^{-2}, \mathrm{RE}=13.80 \%$ for the PLSR model. However PLSR model might be more suitable than MLR model in order to predict the nitrogen contents at the heading stage using the hyperspectral reflectance because not only the robust of PLSR models but also co-linearity in MLR models (Wold et al., 2001). Moreover, PLSR models have more sensitive than MLR models for the inhomogeneous results as shown in the results of verification using multiyear models. It might be one of the reasons that PLSR models are better than MLR models when the biophysical, physiological or biochemical characteristics are estimated by hyperspectral reflectance.

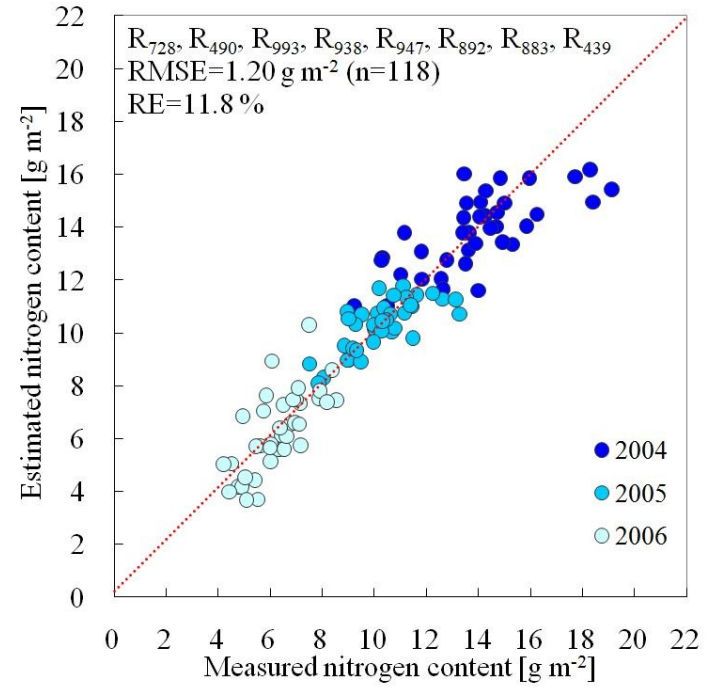

(a) MLR analysis

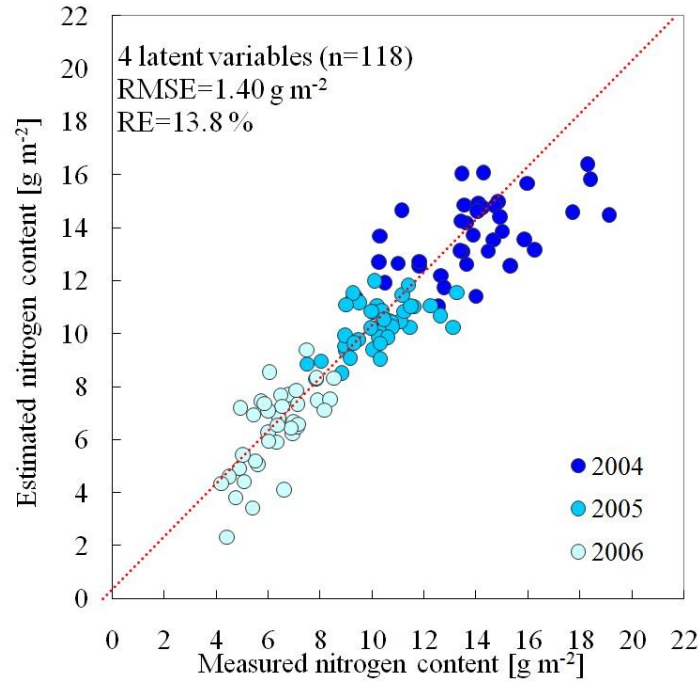

(b) PLSR analysis

Fig. 7. General-purpose prediction model of MLR and PLSR analysis for nitrogen content at the heading stage. 
Therefore, it is important to cumulate the nitrogen content and the hyperspectral reflectance at the heading stage to establish a general-purpose prediction model. Even though there were differences in the environmental variables; for weather conditions and amount of nitrogen fertilizer, it was possible to establish a general-purpose nitrogen content prediction model using airborne hyperspectral remote sensing.

There were still several problems to increasing the precision of the model. The reflectance of rice plants taken by the airborne hyperspectral sensor consisted of a mixture of pixels with rice plants and the others, because of its spatial resolution. A ground-based hyperspectral image might be suitable to clearly analyze the absolute reflectance of the objective and compare it with a mixed reflectance (Park et al., 2007; Okamoto et al., 2007). Moreover, a coordinated program may be needed in which understanding of the interaction between radiation and foliar chemistry can progress from leaf model to canopy model to field experiment (Curran, 1989). It would also be necessary to validate the general-purpose prediction model using data from different locations, seasonal stages and vegetation conditions (Tian et al., 2005; Ryu et al., 2009). When the general-purpose protein prediction model is established, it might be possible to harvest the rice plants depending not only on the quantity but also on the quality of rice (Ryu et al., 2010b).

\section{Summary and conclusions}

Airborne hyperspectral remote sensing was adapted to establish a general-purpose prediction model for the nitrogen content of rice plants at the heading stage using three years of data. There was a difference in the accumulated daily radiation (ADR) and the effective cumulative temperature (ECT) between 2004 and other years. Because of the difference in dry mass and nitrogen concentration, there was also significant difference in nitrogen content among the three years. The reflectance of rice plants at the heading stage was influenced by the difference in the number of the sampled plots at panicle initiation stage and the nitrogen concentration.

In the MLR analysis, it was possible to explain the nitrogen content using hyperspectral reflectance as more than $51 \%$ of it by the single-year models and $70 \%$ of it by the multi-year models. The accuracy of the total model was $\mathrm{R}^{2}=0.893$, $\mathrm{RMSE}=1.092 \mathrm{gm}^{-2}$ and $\mathrm{RE}=9.153 \%$ with eight variables. The accuracy of the validated models was not stable because the similarity and difference in the selected variables between each model. The selected important variables were centralized in the blue, red-edge regions and widely decentralized in the NIR region.

In the PLSR model, it was possible to explain the nitrogen content using hyperspectral reflectance as more than $76 \%$ of it by the single-year models and $81 \%$ of it by the multi-year models. The accuracy of the total model was $\mathrm{R}^{2}=0.837$, $\mathrm{RMSE}=1.401 \mathrm{gm}^{-2}$ and $\mathrm{RE}=11.23 \%$ with four latent variables. The accuracy of the validated models was not stable but better than that of MLR models. 
The similarities and differences of loading weights for each model depending on hyperspectral reflectance might have affected the regression coefficients and the accuracy of each model.

The accuracy of the single-year MLR models was better than that of the single-year PLSR models. However, the accuracy of the multi-year PLSR models was better than that of the multi-year MLR models. PLSR model might be more suitable than MLR model to predict the nitrogen contents at the heading stage using the hyperspectral reflectance because not only the robust of PLSR models but also the sensitivity for the inhomogeneous results. Even though there were differences in the environmental variables (CDR and ECT), it was possible to establish a general-purpose prediction model for the nitrogen content at the heading stage using airborne hyperspectral remote sensing.

\section{Acknowledgments}

This work was supported by the Japan Society for the Promotion of Science KAKENHI (B(2): 13306019) and the Ministry of Agriculture, Forestry and Fisheries (Project No. 1669, 2004). We are grateful to Professor Tatsuya Inamura of Kyoto University of Agriculture Sciences for assistance in rice management at the Takatsuki Experimental Farm of the Graduate School of Agriculture, Kyoto University.

\section{References}

Angus, J.F., Sudjadi, M., Fazekas de st. Groth, C., Mulyani, N.S., Hadiwahyono, D.M., Wetselaar, R., 1990. Simulating nitrogen response of irrigated rice. Plant Soil, 127, 219-229.

Blackburn, G.A., 1998. Quantifying chlorophylls and caroteniods at leaf and canopy scales: an evaluation of some hyperspectral approaches. Remote Sens. Environ. 66(3), 273-285.

Blackmore, S., 1994. Precision farming: an introduction. Outlook Agric. 23(4), 275-280.

Casanova, D., Epema, G.F., Goudriaan, J., 1998. Monitoring rice reflectance at field level for estimating biomass and LAI. Field Crops Res. 55, 83-92.

Casanova, D., Goudriaan, J., Bosch, A.D., 2000. Testing the performance of ORYZA1, an explanatory model for rice growth simulation, for Mediterranean conditions. Eur. J. Agron. 12, 175-189.

Chang, K.W., Shen, Y., Lo, J.C., 2005. Predicting rice yield using canopy reflectance measured at booting stage. Agron. J. 97, 872-878.

Chappelle, E.W., McMurtery III, Kim, M.S., 1991. Identification of the pigment responsible for the blue fluorescence band in the laser induced fluorescence (LIF) spectra of green plants, and the potential use of this band in remotely estimating rates of photosynthesis. Remote Sens. Environ. 36, 213-218.

Chen, Q., Huang, J.F., Wang, X.Z., Wang, R.C., 2003. In situ hyperspectral data analysis for pigment content estimation of rice leaves. J. Zhejiang Univ. Sci. 4(6), 727-733. 
Curran, P.J., Dungan, J.L., Macler, B.A., Plummer, S.E., 1991. The effect of a red leaf pigment on the relationship between red edge and chlorophyll concentration. Remote Sens. Environ. 35, 69-76.

Curran, P.J., 1989. Remote sensing of foliar chemistry. Remote Sens. Environ. 30, 271-278.

Demetriades-shah, T.H., Steven, M.D., Clark, J.A., 1990. High resolution derivative spectra in remote sensing. Remote Sens. Environ. 33, 55-64.

Evri, M., Akiyama, T., Kawamura, K., 2008. Spectrum analysis of hyperspectral red edge position to predict rice biophysical parameters and grain weight. Jpn. Soc. Photogramm. Remote Sen. 47(2), 415.

Green, R.O., Eastwood, M.L., Sarture, C.M., Chrien, T.G., Aronsson, M., Chippendale, B.J., Faust, J.A., Pavri, B.E., Chovit, C.J., 1998. Imaging spectroscopy and the airborne visible/infrared imaging spectrometer (AVIRIS). Remote Sens. Environ. 65, 227-248.

Hache, C., Shibusawa, S., Sasao, A., 2005. Discriminating conventional and conservation agricultural management practices with airborne multispectral imagery. Agric. Ecosyst. Environ. 111, 354-366.

Inamura, T., Hamada, H., Iida, K., Umeda, M., 2003. Correlation of the amount of nitrogen accumulated in the aboveground biomass at panicle initiation and nitrogen content of soil with the nitrogen uptake by lowland rice during the period from panicle initiation to heading. Plant Prod. Sci. 6, 302-308.

Inoue, E., Mihara, Y., Tsuboi, Y., 1963. Agro-meteorological studies on rice growth in Japan. Agric. Meteor. 2, 85-107.

Inoue, Y., 2003. Synergy of remote sensing and modeling for estimating ecophysiological processes in plant production. Plant Prod. Sci. 6, 3-16.

Inoue, Y., Kurosu, T., Maeno, H., Uratsuka, S., Kozu, T., Dabrowska-Zielinska, K., Qi. J., 2002. Season-long daily measurements of multifrequency ( $\mathrm{Ka}, \mathrm{Ku}, \mathrm{X}, \mathrm{C}$, and $\mathrm{L}$ ) and full-polarization backscatter signatures over paddy rice field and their relationship with biological variables. Remote Sens. Environ. 81, 194-204.

Inoue, Y., Penuelas, J., 2001. An AOTF-based hyperspectral imaging system for field use in ecophysiological and agricultural applications. Int. J. Remote Sens. 22(18), 3883-3888.

Inoue, Y., Penuelas, J., Miyata, A., Mano, M., 2008. Normalized difference spectral indices for estimating photosynthetic efficiency and capacity at a canopy scale derived from hyperspectral and $\mathrm{CO}_{2}$ flux measurements in rice. Remote Sens. Environ. 112, 156-172.

Islam, M.S., Morison, J.I.L., 1992. Influence of solar radiation and temperature on irrigated rice grain yield in Bangladesh. Field Crops Res. 30, 13-28.

Japan Meteorological Agency, 2007. The past meteorological data. $<$ http://www.data.jma.go.jp/obd/stats/etrn/index.php> (accessed 02.03.07).

Kimura, R., Okada, S., Miura, H., Kamichika, M., 2004. Relationships among the leaf area index, moisture availability, and spectral reflectance in an upland rife field. Agric. Water Manage. 69, 83- 
100.

Lee, Y.J., Yang, C.M., Chang, K.W., Shen, Y., 2008. A simple spectral index using reflectance of $735 \mathrm{~nm}$ to assess nitrogen status of rice canopy. Agron. J. 100, 205-212.

Lewis, M., Jooste, V., Gasparis, A.A., 2001. Discrimination of arid vegetation with airborne multispectral scanner hyperspectral imagery, IEEE Trans. Geosci. Remote Sen. 39(7), 1471-1479.

Lichtenthaler, H.K., 1988. Remote sensing of chlorophyll fluorescence in oceanography and in terrestrial vegetation: an introduction. In: H.K. Lichtenthaler (Editor), Applications of Chlorophyll Fluorescence. Kluwer, Dordrecht, 287-297.

Liu, Z.Y., Huang, J.F., Tao, R.X., 2008. Characterizing and estimating fungal disease severity of rice brown spot with hyperspectral reflectance data. Rice Sci. 15(3), 232-242.

Micol, R., Michele, M., Mirco, M., Giovanni, M., Sergio, C., Lorenzo, B., Valentina, P., Alessandro, C., Guenther, S., Roberto, C., 2010. High resolution field spectroscopy measurements for estimating gross ecosystem production in a rice field. Agric. Forest Meteor. 150, 1283-1296.

Moya, I., Guyot, G., Goulas, Y., 1992. Remotely sensed blue and red fluorescence emission for monitoring vegetation. ISPRS J. Photogramm. Remote Sens. 47, 205-231.

Nakano, H., Morita, S., 2008. Effects of time of first harvest, total amount of nitrogen, and nitrogen application method on total matter yield in twice harvesting of rice. Field Crops Res. 105, 40-47.

Nguyen, H.T., Lee, B.W., 2006. Assessment of rice leaf growth and nitrogen status by hyperspectral canopy reflectance and partial least square regression. Eur. J. Agron. 24, 349-356.

Ntanos, D.A., Koutroubas, S. D. 2002. Dry matter and N accumulation and translocation for Indica and Japonica rice under Mediterranean conditions. Field Crops Res. 74, 93-101.

Okamoto, H., Murata, T., Kataoka, T., Hata, S., 2007. Plant classification for weed detection using hyperspectral imaging with wavelet analysis. Weed boil. Manage. 7, 31-37.

Park, B., Windham, W.R., Lawrence, K.C., Smith, D.P., 2007. Contaminant classification of poultry hyperspectral imagery using a spectral angle mapper algorithm. Biosyst. Eng. 96, 323-333.

Rock, B.N., Hoshizaki, T., Miller, J.R., 1988. Comparison of in situ and airborne spectral measurement of the blue shift associated with forest decline. Remote Sens. Environ. 24, 109-127.

Ryu, C.S., Suguri, M., Iida, M., Umeda, M., 2010a. Investigation into possibility of methane fermentation digested sludge as liquid fertilizer for paddy field. J. Eng. Agric. Environ. Food 3(1), $32-37$.

Ryu, C.S., Suguri, M., Nishiike, Y., Umeda, M., 2005. Making nitrogen contents model using hyperspectral remote sensing and estimation nitrogen contents by nitrogen content model. J. Jpn. Soc. Agric. Mach. 67(6), 47-54 (in Japanese, with English abstract).

Ryu, C.S., Suguri, M., Umeda, M., 2007. Estimation and comparison of nitrogen contents model of rice plant using remote sensing. J. Jpn. Soc. Agric. Mach. 69(3), 43-50 (in Japanese, with English abstract). 
Ryu, C.S., Suguri, M., Umeda, M., 2009. A model for predicting the nitrogen content of rice at panicle initiation stage using data from airborne hyperspectral remote sensing. Biosyst. Eng. 104, 465-475.

Ryu, C.S., Suguri, M., Iida, M., Umeda, M., Lee, C.K., 2010b. Integrating remote sensing and GIS for prediction of rice protein contents. Prec. Agric. in press.

Seager, S., Turner, E.L., Schafer, J., Ford, E.B. 2005. Vegetation's red edge: A possible spectroscopic biosignature of extraterrestrial plants. Astrobiology. 5, 372-390.

Shibayama, M., Sakamoto, T., Inoue, A., Morita, K., Takahashi, W., Kimura, A., 2009. Continuous monitoring of visible and near-infrared band reflectance from a rice paddy for determining nitrogen uptake using digital camera. Plant Prod. Sci. 12(3), 293-306.

Stroppiana, D., Boschetti, M., Brivio, P.A., Bocchi, S., 2009. Plant nitrogen concentration in paddy rice from field canopy hyperspectral radiometry. Field Crops Res. 111, 119-129.

Ta, T., Ohira, K., 1982. Effects of temperature and light intensity on the uptake and assimilation of $15 \mathrm{~N}-$ labeled ammonium and nitrate in Indica and Japonica rice plants. Soil Sci. Plant Nutr. 28(1), 79-90.

Takahashi, W., Nguyen-Cong, V., Kawaguchi, S., Minamiyama, M., Ninomiya, S., 2000. Statistical models for prediction of dry weight and nitrogen accumulation based on visible and near-infrared hyper-spectral reflectance of rice canopies. Plant Prod. Sci. 3(4), 377-386.

Thenkabail, P.S., Smith, R.B., De Pauw, E., 2000. Hyperspectral vegetation indices and their relationships with agricultural crop characteristics. Remote Sens. Environ. 71(2), 158-182.

Tian, Y., Zhu, Y., Cao, W., 2005. Monitoring leaf photosynthesis with canopy spectral reflectance in rice. Photosynthetica 43(4), 481-489.

Urata, T., Nishigaki, S., 2001. Selection of rice variety Hinohikari with good eating quality and its cultivative characteristics, Bull. Osaka Agric. Forest Res. Ctr. 37, 56-57.

Volkan Bilgili, A., Van Es, H.M., Akbas, F., Durak, A., Hively, W.D., 2010. Visible-near infrared reflectance spectroscopy for assessment of soil properties in a semi-arid area of Turkey. J. Arid Environ. 74, 229-238.

Wang, F.M., Huang, J.F., Wand, X.Z., 2007. Identification of optimal hyperspectral bands for estimation of rice biophysical parameters. J. Integr. Plant Biol. 50(3), 291-299.

Wold, S., Sjöström, M., Eriksson, L., 2001. PLS-regression: a basic tool of chemometircs. Chemom. Intell. Lab. Syst. 58, 109-130.

Yanai, J., Lee, C.K., Umeda, M., Kosaki, T., 2000. Spatial variability of soil chemical properties in a paddy field. Soil Sci. Plant Nutr. 46(2), 473-482.

Yang, C.M., 2010. Assessment of the severity of bacterial leaf blight in rice using canopy hyperspectral reflectance. Prec. Agric. 11, 61-81.

Yang, C.M., Chen, R.K., 2004. Modeling rice growth with hyperspectral reflectance data. Crop Sci. 44(4), 1283-1290. 
Yi, Q.X., Huang, J.F., Wang, F.M., Wang, X.Z., Liu, Z.Y., 2007. Monitoring rice nitrogen status using hyperspectral reflectance and artificial neural network. Environ. Sci. Technol. 41, 6770-6775.

Yoshida, H., Horie, T., Shiraiwa, T., 2008. A model for explaining genotypic and environmental variation in vegetative biomass growth in rice based on observed LAI and leaf nitrogen content, Field Crops Res. 108, 222-230.

Yoshida, S., 1981. Fundamentals of rice crop science. Int. Rice Res. Inst., Los Banõs, Philippines.

Yoshida, S., Parao, F.T., 1976. Climatic influence on yield and yield components of lowland rice in the tropics. In: Climate and Rice, Int. Rice Res. Inst., Los Banõs, Philippines, 471-494.

Zarco-Tehada, P.J., Miller, J.R., Noland, T.L., Mohammed, G.H., Sampson, P.H., 2001. Scaling-up and model inversion methods with narrowband optical indices for chlorophyll content estimation in closed forest canopies with hyperspectral data. IEEE Trans. Geosci. Remote Sen. 39(7), 1491-1507. 